\title{
Immunotherapy in hematologic malignancies
}

\author{
R.R. Kansara $M D^{*}$ and C. Speziali $M D^{*}$
}

\begin{abstract}
The management of hematologic malignancies has traditionally relied on chemotherapy regimens, many of which are still in use today. However, with advancements in the knowledge of tumour pathophysiology, therapies are continually evolving. Monoclonal antibodies against specific targets on tumour cells are now widely used to treat hematologic malignancies, either in combination with chemotherapy or as single agents. Rituximab, a monoclonal antibody against the CD20 antigen, is a good example of successful monoclonal antibody therapy that has improved outcomes for patients with B cell non-Hodgkin lymphomas. Monoclonal antibodies are now being used against the immune checkpoints that function to inhibit $T$ cell activation and subsequent tumour eradication by those cytotoxic T cells. Such therapies enhance T cell-mediated tumour eradication and are widely successful in treating patients with solid tumours such as malignant melanoma. Now, they are slowly finding their place in the management of hematologic neoplasms. Even though, currently, immune checkpoint inhibitors are used for relapsed or refractory hematologic neoplasms, trials are ongoing to evaluate their role in frontline treatment. Our review focuses on the current use of immunotherapies in various hematologic malignancies.
\end{abstract}

Key Words Immunotherapy, hematologic malignancies, PD-1 inhibitors, pembrolizumab, nivolumab, ipilimumab, BiTe therapy

Curr Oncol. 2020 April:27(S2)124-131

www.current-oncology.com

\section{INTRODUCTION}

Hematologic malignancies are complex set of disorders that are common in incidence. Per Canadian cancer statistics, non-Hodgkin lymphoma (NHL) is the most common hematologic neoplasm, followed by leukemia, multiple myeloma (MM), and Hodgkin lymphoma (HL) ${ }^{1}$. Because each subtype is unique, treatments are tailored based on a variety of factors, including pathology diagnosis, biomarkers, stage of disease, and the patient's clinical characteristics. Fortunately, with currently available chemotherapies, common entities such as diffuse large B cell lymphoma (DLBCL) and HL are potentially curable. In contrast, follicular lymphoma (FL) and MM are incurable, but treatable, neoplasms. In disease entities such as MM, consolidation with upfront autologous stem-cell transplantation (ASCT) is available in addition to chemotherapy for those who are eligible. Challenges arise when patients relapse during or after initial therapy. The prognosis for such patients could be guarded. Many such patients are treated with high-dose chemotherapy and ASCT, if not already administered in their upfront regimen; however, better treatments are still needed, especially for those who are not eligible for stem-cell transplantation (SCT) or who relapse after SCT.
Monoclonal antibodies represent a breakthrough in the management of hematologic malignancies. When combined with chemotherapy, rituximab (a chimeric antibody against the CD20 molecule on the surface of B cells) has improved outcomes for patients with DLBCL $^{2-4}$ and FL or indolent B cell lymphomas ${ }^{5-7}$. Brentuximab, a chimeric conjugate antibody against the CD30 antigen present on the surface of neoplastic cells, has improved outcomes for patients with $\mathrm{HL}^{8,9}$. Similarly, daratumumab (a monoclonal antibody against the CD38 antigen expressed on the surface of plasma cells) has been associated with better outcomes than those seen with historical combination therapies in patients with relapsed $\mathrm{MM}^{10-12}$.

Some of the currently available monoclonal antibodies modulate $\mathrm{T}$ cell activation against tumour cells and assist with tumour eradication. Generally, T cells are activated when foreign antigens are processed by antigen-presenting cells and presented to T cells through the major histocompatibility-antigenic peptide complex, which signals the $\mathrm{T}$ cell receptors on the surface of $\mathrm{T}$ cells to activate a $\mathrm{T}$ cell-mediated immune response ${ }^{13}$. Intercellular interactions, such as the binding of B7 proteins on antigen-presenting cells to CD28 on T cells, also assist with T cell stimulation ${ }^{14}$. Tumour cells evade that process 
by expressing molecules on their surface that switch off the process to evade T cell-mediated cell death. PD-Ll and PD-L2, which are expressed in several tumour subtypes, bind to PD receptors on T cells, resulting in T cell inactivation and immune tolerance of the tumour ${ }^{15}$. Similarly, CTLA-4 is expressed on T cells, and if bound to B7 protein on the surface of antigen-presenting cells or tumour cells, also results in T cell inactivation ${ }^{14}$. Antibodies that interfere with the PD-1 and CTLA- 4 systems could thus inhibit those processes by disengaging PD-L1/-L2 and CTLA- 4 from their respective receptors, allowing for $\mathrm{T}$ cell activation and, subsequently, tumour eradication. Inhibitors of PD-Ll and CTLA- 4 have been associated with measurable success in treating solid malignancies, and their use is now expanding to encompass hematologic malignancies.

Another recent advance is the introduction of bispecific T cell engagers ("BiTE therapy"). These bi-specific antibodies link tumour cells to $\mathrm{T}$ cells ${ }^{16}$. Blinatumomab is a bi-specific antibody that links CD19 on the surface of $B$ cells and malignant cells to CD3 antigen on the surface of $\mathrm{T}$ cells, leading to $\mathrm{T}$ cell activation ${ }^{17}$.

In the present review, we focus on the current use of PD-1 inhibitors, CTLA-4 inhibitors, and BiTE therapy for hematologic malignancies. Our review does not include a discussion of chimeric antigen receptor T cell therapy, which is discussed separately in this supplement to Current Oncology.

\section{REVIEW}

\section{PD-1 Inhibitors}

The PD-1 inhibitors include agents such as pidilizumab, nivolumab, and pembrolizumab, all of which have been evaluated for both safety and efficacy in hematologic malignancies.

\section{Pidilizumab}

Berger and colleagues ${ }^{18}$ conducted one of the earlier trials evaluating the safety of pidilizumab in patients with advanced-stage hematologic malignancies after chemotherapy or SCT, or both. In their phase I study in 17 patients, which included individuals with NHL, HL, MM, chronic lymphocytic leukemia (CLL), and acute myeloid leukemia (AML), a single dose of pidilizumab was delivered using an escalation schedule of $0.2-6 \mathrm{mg} / \mathrm{kg}$, without any dose-limiting toxicities being observed (Table I). Median survival was approximately 25 weeks, including 6 patients (35\%) with extended survival of approximately 60 weeks. Of the latter 6 patients, 1 had FL, 1 had AML, 1 had HL, 1 had MM, and 2 had CLL. Subsequently, in a phase II trial, Armand et al ${ }^{19}$ administered pidilizumab after ASCT in patients with DLBCL, primary mediastinal B cell lymphoma (PMBCL), and transformed indolent NHL. Patients received 3 cycles of intravenous pidilizumab $1.5 \mathrm{mg} / \mathrm{kg}$ starting 30-90 days after SСт. Of the 66 patients who received planned therapy with pidilizumab (two thirds of whom had de novo DLBCL), 16-month progression-free survival (PFS) was $72 \%$. Treatment was fairly well tolerated, with only $19 \%$ and $8 \%$ of patients experiencing grade $3-4$ neutropenia and thrombocytopenia respectively. Pidilizumab was subsequently trialled in patients with relapsed FL after 1-4 lines of previous therapies had failed ${ }^{20}$. In that phase II trial, patients received pidilizumab $3 \mathrm{mg} / \mathrm{kg}$ once monthly for up to 12 cycles maximum, together with rituximab $375 \mathrm{mg} / \mathrm{m}^{2}$ once weekly for 4 treatments, beginning at approximately day 17 after the initial pidilizumab infusion. The study successfully enrolled 30 patients, all of whom had previously received rituximab. At a median follow-up of 15.4 months, $66 \%$ had attained an objective response [ $52 \%$ being complete responses (CRs)], with a median PFS of 18.8 months overall. No grade 3 or 4 toxicities were encountered. Those safety and efficacy data for pidilizumab are encouraging; however, the drug has not attained as much popularity as its counterparts nivolumab and pembrolizumab in hematologic malignancies.

\section{Nivolumab}

Lesokhin et al. ${ }^{21}$ conducted one of the earlier trials evaluating the safety of nivolumab in patients with hematologic neoplasms. Their phase I study included 81 patients with relapsed or refractory (R/R) NHL (including T cell $\mathrm{NHL}$ ), classical Hodgkin lymphoma (CHL), and MM after at least 1 prior line of therapy (Table II). The group included 10 patients with FL,

TABLE I Pidilizumab in hematologic malignancies

\begin{tabular}{|c|c|c|c|c|c|c|c|c|}
\hline \multirow[t]{2}{*}{ Reference } & \multirow[t]{2}{*}{ Phase } & \multirow{2}{*}{$\begin{array}{l}\text { Pts } \\
\text { (n) }\end{array}$} & \multirow[t]{2}{*}{ Histology } & \multirow[t]{2}{*}{ Schedule } & \multirow{2}{*}{$\begin{array}{c}\text { ORR } \\
(\%)\end{array}$} & \multirow{2}{*}{$\begin{array}{c}\text { CR } \\
(\%)\end{array}$} & \multicolumn{2}{|c|}{ Median } \\
\hline & & & & & & & PFS & OS \\
\hline $\begin{array}{l}\text { Berger et al., } \\
2008^{18}\end{array}$ & 1 & 17 & $\begin{array}{l}\text { Relapsed or refractory } \mathrm{NHL} \text {, } \\
\mathrm{CLL}, \mathrm{CHL}, \mathrm{MM}, \mathrm{AML}\end{array}$ & $0.2-6 \mathrm{mg} / \mathrm{kg}$ once & $N R$ & 6 & NR & $\begin{array}{l}25 \pm 27 \\
\text { Weeks }\end{array}$ \\
\hline$\underset{2013^{19}}{\text { Armand et al., }}$ & II & 66 & $\begin{array}{l}\text { Relapsed or refractory } \\
\text { DLBCL,PMBCL, trINHL } \\
\text { achieving at least a partial } \\
\text { response after ASCT }\end{array}$ & $\begin{array}{l}1.5 \mathrm{mg} / \mathrm{kg} \text { every } 6 \text { weeks } \\
\text { for } 3 \text { doses after ASCT }\end{array}$ & 51 & 34 & $\begin{array}{c}72 \% \\
\text { at } 16 \\
\text { months }^{\mathrm{a}}\end{array}$ & $\begin{array}{c}85 \% \\
\text { at } 16 \\
\text { months }^{\text {a }}\end{array}$ \\
\hline $\begin{array}{l}\text { Westin et al., } \\
2014^{20}\end{array}$ & II & 29 & Relapsed or refractory FL & $\begin{array}{c}3 \mathrm{mg} / \mathrm{kg} \text { every } 4 \text { weeks for } \\
4 \text { doses (up to } 12 \text { doses } \\
\text { if stable disease or better), } \\
\text { with rituximab every } \\
1 \text { week for } 4 \text { doses }\end{array}$ & 66 & 52 & $\begin{array}{l}18.8 \\
\text { Months }\end{array}$ & $N R$ \\
\hline
\end{tabular}

\footnotetext{
a Not median.
}

Pts = patients; $\mathrm{ORR}=$ objective response rate; $\mathrm{CR}=$ complete response; $\mathrm{PFS}=$ progression-free survival; $\mathrm{OS}=$ overall survival; $\mathrm{NHL}=$ non- $\mathrm{Hodgkin}$ lymphoma; $\mathrm{CLL}=$ chronic lymphocytic leukemia; $\mathrm{CHL}=$ classical Hodgkin lymphoma; $\mathrm{MM}=$ multiple myeloma; $\mathrm{AML}=$ acute myeloid leukemia; $\mathrm{NR}=$ not reported; $\mathrm{DLBCL}=$ diffuse large $\mathrm{B}$ cell lymphoma; $\mathrm{PMBCL}=$ primary mediastinal $\mathrm{B}$ cell lymphoma; trlNHL $=$ transformed indolent $\mathrm{NHL}$; $\mathrm{ASCT}=$ autologous stem-cell transplantation; $\mathrm{FL}=$ follicular lymphoma. 


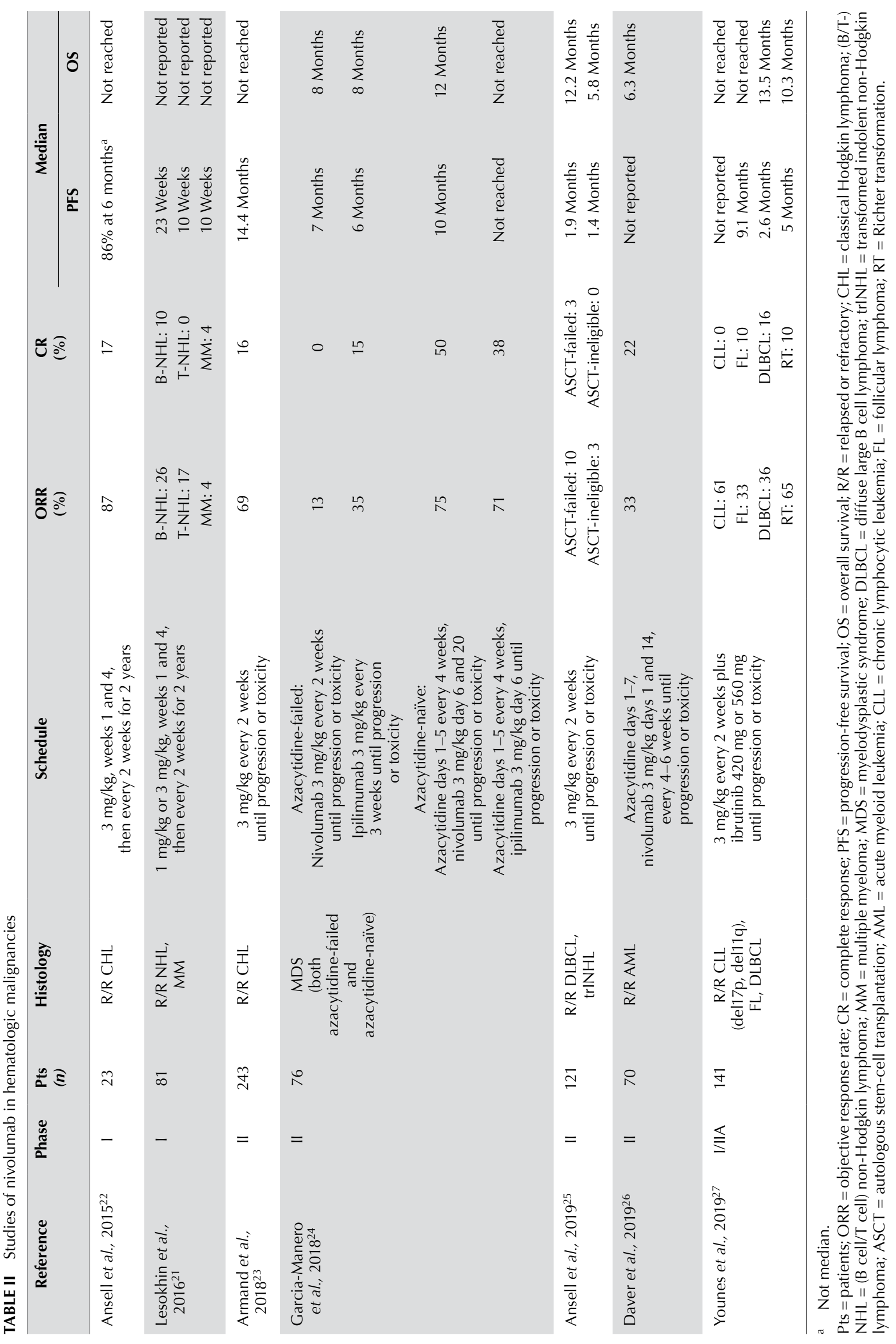


11 with DLBCL, 10 with other subtypes of B cell lymphoma, 23 with T cell lymphoma, and 27 with MM. Patients received nivolumab $1 \mathrm{mg} / \mathrm{kg}$ or $3 \mathrm{mg} / \mathrm{kg}$ administered in weeks 1 and 4 , followed by 1 administration every 2 weeks for up to 2 years. Nivolumab was well tolerated: only 18 patients (22\%) experienced grade 3 or greater toxicities. Immune toxicities were noted in 28 patients (35\%) and were resolved in 13 patients without a need for immunosuppressive treatment or interruption of nivolumab. In this trial, the objective response was an encouraging $40 \%$ for patients with FL and DLBCL; outcomes for those with T cell lymphoma and MM were not as robust, with objective response rates of only $17 \%$ and $4 \%$ respectively.

Additional trials have resulted in impressive outcomes after nivolumab administration for patients with $\mathrm{R} / \mathrm{R} \mathrm{CHL}{ }^{22,23}$. Those results are not surprising considering that the hallmark cells in CHL, the Reed-Sternberg cells, frequently demonstrate amplification of chromosome 9p24 (which also includes the JAK2 locus), resulting in overexpression of PD-L1 and PD-L2 ${ }^{28}$. Ansell and colleagues ${ }^{22}$ demonstrated that, in 23 patients with $\mathrm{R} / \mathrm{R} \mathrm{CHL}$, the objective response after single-agent nivolumab $(3 \mathrm{mg} / \mathrm{kg}$ in weeks 1 and 4 , followed by 1 administration every 2 weeks for up to 2 years) was an unprecedented $87 \%$ (including $17 \%$ CRs). In the trial, ASCT and brentuximab had failed for almost two thirds of the patients, a subset that would otherwise have had a dismal outcome. Importantly, nivolumab was fairly well tolerated: only $22 \%$ of the patients experienced grade 3 or greater toxicities, which were mostly reversible. At 6 months, the PFS was an encouraging 86\%. Updated results of the trial have now been presented, and at a median follow-up of 86 weeks, $50 \%$ of the responding patients have experienced durable responses ${ }^{29}$.

A larger multicentre phase II study evaluating nivolum$\mathrm{ab}$ in patients with relapsed CHL (CheckMate 205) was subsequently conducted ${ }^{23}$. Three cohorts were evaluated: cohort A included patients who were brentuximab-naïve $(n=63)$; cohort B included those who had previously received brentuximab after ASCT $(n=80)$; and cohort C included patients who had received brentuximab before ASCT, or after ASCT, or both before and after $(n=100)$. Patients received nivolumab $3 \mathrm{mg} / \mathrm{kg}$ every 2 weeks until toxicity, progression, death, withdrawal of consent, or study end (at least 5 years of follow-up). The objective response rate (ORR) was $69 \%$ (including $16 \%$ CRs), with a median PFS of 14.7 months. Serious adverse events were noted in only $12 \%$ of patients.

Nivolumab is now widely used in patients with CHL who have relapsed after ASCT, or brentuximab, or both. Unlike the results in CHL, results from a recent study of nivolumab in 121 patients with R/R DLBCL who were not eligible for ASCT, or for whom ASCT failed, were discouraging; the ORR was only $3 \%$ in those ineligible for ASCT and $10 \%$ in those for whom ASCT failed ${ }^{25}$.

Inhibitors of PD-1 are now being trialled in combination with targeted agents. Younes et al. ${ }^{27}$ studied combination nivolumab-ibrutinib (the latter being a Bruton tyrosine kinase inhibitor) in 141 patients with R/R B cell NHL, including CLL and Richter transformation (RT). The safety profile was acceptable, but the onRs for patients with FL and DLBCL were discouraging (33\% and $36 \%$ respectively). For patients with CLL and RT, the oRRs were $61 \%$ and $65 \%$ respectively. Whether the greater response in patients with RT was attributable to ibrutinib or to nivolumab or to the combination is unclear; however, the median survival of patients with RT was 10.3 months, which is similar to the median survival with single-agent pembrolizumab in patients with RT (10.7 months) ${ }^{30}$.

The use of nivolumab is now expanding beyond lymphomas. Yang et al. ${ }^{31}$ demonstrated upregulation of PD-1 receptor, $\mathrm{PD}-\mathrm{L} 1 /$-L2, and CTLA-4 in patients with myelodysplastic syndrome (MDS), AML, and chronic myelomonocytic leukemia. They also demonstrated that hypomethylating agents such as azacytidine, which are frequently used in those entities, led to upregulation of immune checkpoint antigens-hence justifying the use of checkpoint inhibitors in patients with myeloid neoplasms. Berger et al. ${ }^{18}$ had included patients with MDS and AML in their phase I study of pidilizumab; for those patients, the ORR was $13 \%$. A phase II study evaluating the safety and efficacy of nivolumab, or ipilimumab, or both, with or without azacytidine in patients with treated or untreated MDS has been reported ${ }^{32}$. Of 37 patients with MDS, 13 received azacytidine with nivolumab, 15 received nivolumab alone, and 9 received ipilimumab alone. The ORR was $69 \%$ in the combination arm, $0 \%$ in the nivolumab arm, and $22 \%$ in the ipilimumab arm, all with tolerable toxicities. Combining hypomethylating agents with PD-1 inhibitors appeared to be safe. Garcia-Manero et al. ${ }^{24}$ updated those results for a total of 76 patients: The resulting ORRs were, respectively, $75 \%, 71 \%, 13 \%$, and $35 \%$ for treatment with azacytidine-nivolumab, azacytidineipilimumab, nivolumab alone, and ipilimumab alone. Similarly, Daver and colleagues ${ }^{26}$ reported outcomes for 70 patients with relapsed AML treated with a combination nivolumab-azacytidine: 15 (21\%) attained a CR, and an additional 7 patients experienced a hematologic response.

\section{Pembrolizumab}

Like nivolumab, pembrolizumab has also found success in the management of R/R CHL (Table III). The KEYNOTE-013 trial evaluated the safety and efficacy of pembrolizumab in patients with $\mathrm{R} / \mathrm{R}$ hematologic neoplasms including $\mathrm{CHL}$, FL, DLBCL, PMBCL, MM, and MDS. The results for independent cohorts with CHL and PMBCL are now published ${ }^{33,37}$. In the relevant trial, 31 patients with cHL received pembrolizumab $10 \mathrm{mg} / \mathrm{kg}$ every 2 weeks for up to 2 years or until progression or unacceptable toxicity ${ }^{33}$. All patients had previously received brentuximab, and in $71 \%$, ASCT had failed. The ORR was $65 \%$ (a $16 \%$ rate of $\mathrm{CR}$ ), similar to that with nivolumab. An impressive $90 \%$ of the patients experienced some reduction in their tumour burden. At a median follow-up of 17.6 months, 1-year PFS was approximately $50 \%$. Even though $68 \%$ of the patients experienced some drug-induced toxicities, grade 3 toxicities were noted in only 5 patients (16\%).

The larger KEYNOTE-087 trial was subsequently conducted for patients with $\mathrm{R} / \mathrm{R} \mathrm{CHL}^{38}$. That study enrolled 210 patients, assigning them to 3 cohorts: cohort 1 included patients for whom both ASCT and brentuximab had failed ( $n=69)$; cohort 2 included patients for whom brentuximab had failed, but who couldn't undergo SCT $(n=81)$; and cohort 3 included patients who underwent SCT, but who had not received brentuximab $(n=60)$. Patients received pembrolizumab $200 \mathrm{mg}$ every 3 weeks for up to 2 years or 
TABLE III Studies of pembrolizumab in hematologic malignancies

\begin{tabular}{|c|c|c|c|c|c|c|c|c|}
\hline \multirow[t]{2}{*}{ Reference } & \multirow[t]{2}{*}{ Phase } & \multirow{2}{*}{$\begin{array}{l}\text { Pts } \\
(n)\end{array}$} & \multirow[t]{2}{*}{ Histology } & \multirow[t]{2}{*}{ Schedule } & \multirow{2}{*}{$\begin{array}{l}\text { ORR } \\
(\%)\end{array}$} & \multirow{2}{*}{$\begin{array}{l}\text { CR } \\
(\%)\end{array}$} & \multicolumn{2}{|c|}{ Median } \\
\hline & & & & & & & PFS & OS \\
\hline Armand et al., $2016^{33}$ & IB & 31 & $\mathrm{R} / \mathrm{R} \mathrm{CHL}$ & $\begin{array}{l}10 \mathrm{mg} / \mathrm{kg} \text { every } 2 \text { weeks } \\
\text { until progression or toxicity }\end{array}$ & 65 & 16 & $\begin{array}{c}46 \% \\
\text { at } 1 \text { year }\end{array}$ & $\begin{array}{c}100 \% \\
\text { at } 6 \text { months }\end{array}$ \\
\hline $\begin{array}{l}\text { Garcia-Manero et al., } \\
2016^{34}\end{array}$ & $\mathrm{IB}$ & 28 & R/R MDS & 10 mg/kg every 2 weeks ${ }^{b}$ & 4 & 0 & Not reported & $\begin{array}{c}49 \% \\
\text { at } 6 \text { months }\end{array}$ \\
\hline \multirow[t]{2}{*}{ Ding et al., $2017^{30}$} & II & 25 & R/R CLL or RT & 200 mg every 3 weeks ${ }^{b}$ & CLL: 0 & 0 & 2.4 Months & 11.2 Months \\
\hline & & & & & RT: 44 & 11 & 5.4 Months & 10.7 Months \\
\hline \multirow[t]{2}{*}{ Armand et al., $2018^{35}$} & $\mathrm{IB}$ & 21 & $\mathrm{R} / \mathrm{R} \mathrm{PMBCL}$ & $\begin{array}{c}10 \text { mg/kg every } 2 \text { weeks } \\
\text { OR } \\
200 \text { mg every } 3 \text { weeks }{ }^{b}\end{array}$ & 48 & 33 & 10.4 Months & 31.4 Months \\
\hline & II & 53 & $\mathrm{R} / \mathrm{R} \mathrm{PMBCL}$ & 200 mg every 3 weeks ${ }^{b}$ & 45 & 13 & 5.5 Months & Not reached \\
\hline Zinzani et al., $2018^{36}$ & II & 210 & $\mathrm{R} / \mathrm{R} \mathrm{CHL}$ & 200 mg every 3 weeks ${ }^{b}$ & 72 & 27 & 13.7 Months & Not reached \\
\hline
\end{tabular}

a Not median.

b To a maximum of 24 months or any of progression, toxicity, or investigator decision.

Pts = patients; ORR = objective response rate; $\mathrm{CR}=$ complete response; PFS = progression-free survival; OS = overall survival; $\mathrm{R} / \mathrm{R}=$ relapsed or refractory; $\mathrm{CHL}=$ classical Hodgkin lymphoma; $\mathrm{MDS}=$ myelodysplastic syndrome; $\mathrm{CLL}=$ chronic lymphocytic leukemia; $\mathrm{RT}=\mathrm{Richter}$ transformation; $\mathrm{PMBCL}=$ primary mediastinal $\mathrm{B}$ cell lymphoma.

until progression or severe toxicity. For the patients overall, the ORR was $69 \%$ ( $22.4 \%$ CRs) with a 6 -month median duration of response and median survival not reached. Only 14 patients experienced grade 3 or greater toxicities. Updated results noted that, at a median follow-up of 27.6 months, the ORR was $71 \%$, median PFS was 14 months, and median os was not reached ${ }^{36}$.

The efficacy of pembrolizumab and of nivolumab in CHL thus appears similar. The choice of agent in the relapsed setting depends mostly on drug access, scheduling, and physician and patient preference. Considering that pembrolizumab is administered every 3 weeks, and nivolumab, every 2 weeks, patients might tend to select pembrolizumab to prolong the treatment interval. However, recent pharmacokinetics studies have indicated that nivolumab at a fixed dose of $480 \mathrm{mg}$ every 4 weeks is equivalent to the previous every-2-weeks dosing, providing patients with more flexibility ${ }^{39}$.

As in CHL, early results with pembrolizumab in PMBCL are encouraging. The PMBCL cohort in the KEYNOTE-013 trial $(n=19)$ was recently reported ${ }^{37}$. In the first 11 patients, the pembrolizumab dosing schedule was the same as that in the CHL cohort (10 mg/kg every 2 weeks); however, for the remaining patients, the dose was amended to $200 \mathrm{mg}$ every 3 weeks after emerging pharmacokinetic and pharmacodynamic reports about similar exposures. The oRR was $41 \%$ (including $11 \% \mathrm{CRs}$ ), and $81 \%$ of the patients experienced some reduction in tumour burden. At a median follow-up of 11.3 months, the median duration of response was not reached. Pembrolizumab was felt to be safe in that cohort, with only 2 patients experiencing grade 3 or greater toxicities. Extended KEYNOTE-013 data, including the results of the larger KEYNOTE-170 trial of pembrolizumab in PMBCL, were recently presented; at median follow-ups of 29 and 12.5 months respectively, the median duration of response had not been reached, and the 12 -month PFS rates were $47 \%$ and $38 \%{ }^{35}$.

Data have emerged that pembrolizumab is effective not only in CHL and PMBCL, but in patients with CLL and
$\mathrm{RT}^{30}$. Pembrolizumab as a single agent in 28 patients with refractory MDS was associated with an ORR of $15 \%{ }^{34}$.

In patients with $\mathrm{MM}$, initial trials of immunotherapy were associated with a high risk of mortality $y^{40}$. Those trials included KEYNOTE-183, evaluating pembrolizumab in combination with pomalidomide-dexamethasone for R/R MM, and KEYNOTE-185, evaluating pembrolizumab in combination with lenalidomide-dexamethasone for untreated MM. The U.S. Food and Drug Administration therefore halted trials evaluating pembrolizumab in patients with MM. Increased mortality was also noted in the CheckMate 602 trial, evaluating nivolumab in combination with pomalidomidedexamethasone ${ }^{40}$. Thus, in patients with $\mathrm{MM}$, the foregoing inhibitors appear to increase mortality.

The PD-1 inhibitors have been used in patients for whom allogeneic SCT (allo-SCT) has failed. A retrospective review of 31 patients who received either nivolumab or pembrolizumab for relapsed hematologic malignancies after allo-SCT demonstrated an ORR of $77 \%$ (including $50 \%$ CRs). Most of those patients (94\%) had CHL, and hence that outcome is not surprising ${ }^{41}$. A problem noted in the study was the occurrence of treatment-related graft-versus-host disease (GVHD) in more than half the patients. Herbaux et $a l .{ }^{42}$ noted a $30 \%$ risk of GVHD in 20 patients with CHL who received nivolumab after failure of allo-sCT. A large review of patients who received checkpoint inhibitors either before or after allo-SCT confirmed higher rates of GVHD (56\%) and increased mortality from $\mathrm{GVHD}^{43}$.

\section{CTLA-4 Inhibitors}

\section{Ipilimumab}

The most commonly used CTLA-4 inhibitor is ipilimumab. Only small clinical trials have evaluated its safety and efficacy in patients with hematologic malignancies.

Ansell and colleagues ${ }^{44}$ reported a phase I study of ipilimumab in R/R B cell NHL. In that small trial (18 patients), ipilimumab up to $3 \mathrm{mg} / \mathrm{kg}$ could be received once 
per month for 4 doses. The trial showed that ipilimumab could safely be used in patients with hematologic malignancies. Discouragingly, only 2 patients (11\%) attained a clinical response. However, a patient with DLBCL remained in CR without recurrence for more than 31 months from treatment start.

Most other trials have evaluated ipilimumab in patients for whom allo-scT has failed ${ }^{45-47}$. An initial trial of ipilimumab in patients with progressive hematologic neoplasms after allo-scT studied a maximum dose of $3 \mathrm{mg} /$ $\mathrm{kg}^{45}$, noting no dose-limiting toxicities or grade 3 GVHD. In the study, 3 of 27 patients (11\%) experienced an objective response, including 2 patients with CHL who attained a CR. Considering that $3 \mathrm{mg} / \mathrm{kg}$ was well tolerated, another trial was established for patients with relapsed hematologic malignancies after allo-SCT, in which patients could receive ipilimumab up to $10 \mathrm{mg} / \mathrm{kg}^{46}$. In that trial involving 28 patients, 22 were able to receive the $10 \mathrm{mg} / \mathrm{kg}$ dose. Interestingly, no objective responses were seen in patients who received $3 \mathrm{mg} / \mathrm{kg}$; however, of those who received $10 \mathrm{mg} / \mathrm{kg}, 5$ attained a CR (3 with AML, 1 with myeloid sarcoma, 1 with MDS), and 2 attained a partial response (1 with CHL, 1 with plasmacytoma). Even though the higher dose was well tolerated, 5 patients discontinued therapy because of dose-limiting toxicities (4 who developed GVHD, 1 with immune toxicities).

Ipilimumab was recently combined with lenalidomide to treat 17 patients with lymphoid malignancies after SCT (10 after allo-SCT and 7 after ASCT) ${ }^{47}$. Impressively, the ORR was $70 \%$ in patients after allo-sCT (including $40 \%$ CRs). At a median follow-up of 21 months, $90 \%$ of the patients were alive.

Considering the upregulation of CTLA- 4 and PD-L1 antigens in patients with MDS and AML, ipilimumab is also being investigated in that group of patients. Daver et al. ${ }^{48}$ recently presented their cohort of 20 patients who were treated with the triplet nivolumab-ipilimumab-azacytidine, which was associated with an impressive $43 \%$ rate of CRs and $58 \%$ 1-year survival.

\section{BiTE Therapy}

The BiTEs are a class of bi-specific antibodies designed to direct immune effector cells to target and eliminate malignant cells. The most clinically relevant example is blinatumomab, which includes one domain targeting the B cell antigen CD19, and a second domain targeting CD3 on cytotoxic T cells.

An open-label single-arm phase II trial of blinatumomab in $\mathrm{R} / \mathrm{R}$ B cell acute lymphoblastic leukemia (B-ALL) demonstrated efficacy in that difficult-to-treat population, with 25 of 36 patients (69\%) achieving a CR or a CR with incomplete hematologic recovery ${ }^{49}$. High rates of CR were observed in traditionally high-risk patients, including those who had relapsed after allo-sCT and those who had poor-risk genetic features such as Philadelphia chromosome $(\mathrm{Ph})$-positive B-ALL or $\mathrm{t}(4 ; 11)$. Impressively, $88 \%$ of responders achieved a minimal residual disease (MRD)negative remission, and 13 patients were able to proceed to allo-sCT. For the entire cohort, os was 9.8 months $(95 \%$ CI: 8.5 months to 14.9 months).

In the phase III TOWER study, 405 patients 18 years of age and older with R/R Ph-negative B-ALL were randomized 2:1 to receive blinatumomab or conventional chemotherapybased salvage regimens ${ }^{50}$. Rates of CR ( $34 \%$ vs. $\left.16 \%, p<0.001\right)$ and CR with incomplete hematologic recovery ( $44 \%$ vs. $25 \%, p<0.001$ ) were significantly higher with blinatumomab, translating into significantly improved os in the blinatumomab group (7.7 months vs. 4.0 months with traditional salvage regimens; hazard ratio: 0.71; $95 \% \mathrm{CI}: 0.55$ to $0.93 ; p=0.01$ ). Of the patients in each arm, $24 \%$ went on to receive allo-SCT. Adverse events were common in both arms (grade 3 or greater: $87 \%$ in the blinatumomab arm and $92 \%$ in the chemotherapy arm). The most common treatment-related toxicities were fever, headache, and cytopenias, but serious adverse events were relatively common, and fatal adverse events occurred in $19.1 \%$ of the patients receiving blinatumomab. Most of the fatalities were secondary to infectious causes; however, given that patients with R/R B-ALL are highly immunocompromised at baseline, the extent to which blinatumomab contributed to the infectious deaths is unclear. Grade 3 or greater cytokine-release syndrome occurred in $4.9 \%$ of patients in the blinatumomab arm (none occurred in the chemotherapy arm), but grade 3 or greater neurologic events were similar in the two arms (9.4\% vs. $8.3 \%)$.

A single-arm phase II trial of blinatumomab in 45 patients with $\mathrm{R} / \mathrm{R} \mathrm{Ph}$-positive $\mathrm{B}$-ALL resulted in response rates and safety outcomes that were similar to the published experience in Ph-negative B-ALL, suggesting that blinatumomab is a useful agent for $\mathrm{R} / \mathrm{R} \mathrm{B}-\mathrm{ALL}$ in general $^{51}$.

Another potential role for blinatumomab is as consolidation for patients who achieve a cR by traditional criteria, but who remain positive for MRD, defined as disease that is not detectable by microscopy, but that can be measured by specialized techniques (for example, multi-parameter flow cytometry or next-generation sequencing) at a level of $10^{-3}$ or less (that is, fewer leukemic blasts than 1 in 1000 cells). Minimal residual disease status has emerged as the most important predictor of long-term leukemia-free survival in B-ALL. Patients who are MRD-negative after induction chemotherapy do not benefit from allo-SCT in first CR. Gökbuget et al. ${ }^{52}$ therefore studied blinatumomab given for up to 4 cycles in 116 adults in CR, but with MRD-positive B-ALL. Of those patients, $78 \%$ achieved MRD-negative disease after 1 cycle of blinatumomab, with 2 additional responses after treatment cycle 2 . No additional responses were seen beyond cycle 2 . In a landmark analysis, leukemia-free survival (23.6 months vs. 5.7 months) and os (38.9 months vs. 12.5 months) were both significantly greater for patients who converted to MRD-negative disease. Although the study was underpowered to assess such differences, 9 of 36 patients without allo-SCT (25\%) and 36 of 74 with allo-sCT (49\%) after blinatumomab remained in CR at a median follow-up of 24 months, suggesting that blinatumomab might best serve as a bridge to allo-SCT rather than as definitive therapy for those with MRD-positive B-ALL after induction. Safety outcomes were in line with those reported from earlier trials.

Blinatumomab is now being evaluated in B cell lymphomas other than B-ALL. A phase II study evaluated blinatumomab in patients with $\mathrm{R} / \mathrm{R} \mathrm{DLBCL}^{53}$, demonstrating a $43 \%$ ORR (including $19 \% \mathrm{CRs}$ ). At a median follow-up of 11.4 months, median os was only 5 months. Neurologic toxicities, including tremors, were frequently encountered. 
Similarly, a large phase I study evaluated blinatumomab in 76 patients with $\mathrm{R} / \mathrm{R} \mathrm{NHL}^{54}$. The maximal established dose was $60 \mu \mathrm{g} / \mathrm{m}^{2}$ daily, and grade 3 neurologic toxicities occurred in $22 \%$ of patients. For those who were able to tolerate the maximal dose, the ORR was $69 \%$, including an impressive $55 \%$ for patients with DLBCL. Further studies are warranted to establish the role of blinatumomab in managing B cell NHL.

\section{SUMMARY}

The landscape in the management of hematologic malignancies is changing with the introduction of novel therapies. Inhibitors of PD-1 have improved outcomes for patients with R/R CHL and are now commonly used in patients with R/R CHL after failure of ASCT with or without brentuximab. Efficacy data for such inhibitors in patients with CHL after allo-sCT are robust, but at the expense of increased GVHD and its associated mortality. Given the encouraging data for treatment in patients with PMBCL, MDS, and AML, use of these agents might expand in future to include those hematologic disease entities. Response rates in patients with DLBCL and FL are discouraging, and hence additional strategies are being sought. Although outcomes in patients with CLL are debatable, PD-1 inhibitors are showing promise in the management of RT. In contrast, CTLA-4 inhibitors are still finding their roles in patients with hematologic malignancies. Current use is found mostly in clinical trial settings, but given the encouraging data in patients with AML and MDS, further trials might pave the way for their use in such myeloid neoplasms. Blinatumomab is now widely used in managing B-ALL, and trials are ongoing to establish its role in B cell NHL.

\section{ACKNOWLEDGMENTS}

This manuscript was jointly written by RRK and CS. RRK focused on PD-1 and CTLA-4 inhibitors; CS focused on BiTE therapy.

\section{CONFLICT OF INTEREST DISCLOSURES}

We have read and understood Current Oncology's policy on disclosing conflicts of interest, and we declare that we have none.

\section{AUTHOR AFFILIATIONS}

*Section of Medical Oncology/Hematology, Department of Internal Medicine, University of Manitoba, Winnipeg, MB.

\section{REFERENCES}

1. Canadian Cancer Society's Steering Committee. Canadian Cancer Statistics 2018. Toronto, ON: Canadian Cancer Society; 2018.

2. Coiffier B, Thieblemont C, Van Den Neste E, et al. Long-term outcome of patients in the LNH-98.5 trial, the first randomized study comparing rituximab-CHOP to standard CHOP chemotherapy in DLBCL patients: a study by the Groupe d'Etudes des Lymphomes de l'Adulte. Blood 2010;116:2040-5.

3. Pfreundschuh M, Kuhnt E, Trümper L, et al. CHOP-like chemotherapy with or without rituximab in young patients with good-prognosis diffuse large-B-cell lymphoma: 6-year results of an open-label randomised study of the MabThera International Trial (MInT) Group. Lancet Oncol 2011;12:1013-22.

4. Habermann TM, Weller EA, Morrison VA, et al. RituximabCHOP versus CHOP alone or with maintenance rituximab in older patients with diffuse large B-cell lymphoma. J Clin Oncol 2006;24:3121-7.
5. Robak T, Dmoszynska A, Solal-Céligny P, et al. Rituximab plus fludarabine and cyclophosphamide prolongs progressionfree survival compared with fludarabine and cyclophosphamide alone in previously treated chronic lymphocytic leukemia. J Clin Oncol 2010;28:1756-65.

6. Marcus R, Imrie K, Belch A, et al. CVP chemotherapy plus rituximab compared with CVP as first-line treatment for advanced follicular lymphoma. Blood 2005;105:1417-23.

7. Hiddemann W, Kneba M, Dreyling M, et al. Frontline therapy with rituximab added to the combination of cyclophosphamide, doxorubicin, vincristine, and prednisone (CHOP) significantly improves the outcome for patients with advanced-stage follicular lymphoma compared with therapy with CHOP alone: results of a prospective randomized study of the German LowGrade Lymphoma Study Group. Blood 2005;106:3725-32.

8. Connors JM, Jurczak W, Straus DJ, et al. on behalf of the ECHELON-1 study group. Brentuximab vedotin with chemotherapy for stage III or IV Hodgkin's lymphoma. $N$ Engl J Med 2018;378:331-44. [Erratum in: N Engl J Med 2018;378:878]

9. Younes A, Gopal AK, Smith SE, et al. Results of a pivotal phase II study of brentuximab vedotin for patients with relapsed or refractory Hodgkin's lymphoma. J Clin Oncol 2012;30:2183-9.

10. Mateos MV, Dimopoulos MA, Cavo M, et al. on behalf of the ALCYONE trial investigators. Daratumumab plus bortezomib, melphalan, and prednisone for untreated myeloma. $N$ Engl JMed 2018;378:518-28.

11. Dimopoulos MA, Oriol A, Nahi H, etal. on behalf of the POLLuX investigators. Daratumumab, lenalidomide, and dexamethasone for multiple myeloma. N Engl J Med 2016;375:1319-31.

12. Palumbo A, Chanan-Khan A, Weisel K, et al. on behalf of the CASTOR investigators. Daratumumab, bortezomib, and dexamethasone for multiple myeloma. $N$ Engl J Med 2016;375:754-66.

13. York IA, Rock KL. Antigen processing and presentation by the class I major histocompatibility complex. Annu Rev Immunol 1996;14:369-96.

14. Greenfield EA, Nguyen KA, Kuchroo VK. CD28/B7 costimulation: a review. Crit Rev Immunol 1998;18:389-418.

15. Gordon SR, Maute RL, Dulken BW, et al. PD-1 expression by tumour-associated macrophages inhibits phagocytosis and tumour immunity. Nature 2017;545:495-9.

16. Staerz UD, Kanagawa O, Bevan MJ. Hybrid antibodies can target sites for attack by T cells. Nature 1985;314:628-31.

17. Bargou R, Leo E, Zugmaier G, et al. Tumor regression in cancer patients by very low doses of a T cell-engaging antibody. Science 2008;321:974-7.

18. Berger R, Rotem-Yehudar R, Slama G, et al. Phase I safety and pharmacokinetic study of CT-011, a humanized antibody interacting with $\mathrm{PD}-1$, in patients with advanced hematologic malignancies. Clin Cancer Res 2008;14:3044-51.

19. Armand P, Nagler A, Weller EA, et al. Disabling immune tolerance by programmed death-1 blockade with pidilizumab after autologous hematopoietic stem-cell transplantation for diffuse large B-cell lymphoma: results of an international phase II trial. J Clin Oncol 2013;31:4199-206.

20. Westin JR, Chu F, Zhang M, et al. Safety and activity of PD1 blockade by pidilizumab in combination with rituximab in patients with relapsed follicular lymphoma: a single group, open-label, phase 2 trial. Lancet Oncol 2014;15:69-77.

21. Lesokhin AM, Ansell SM, Armand P, et al. Nivolumab in patients with relapsed or refractory hematologic malignancy: preliminary results of a phase Ів study. J Clin Oncol 2016;34:2698-704.

22. Ansell SM, Lesokhin AM, Borrello I, et al. PD-1 blockade with nivolumab in relapsed or refractory Hodgkin's lymphoma. N Engl J Med 2015;372:311-19. 
23. Armand P, Engert A, Younes A, et al. Nivolumab for relapsed/ refractory classic Hodgkin lymphoma after failure of autologous hematopoietic cell transplantation: extended follow-up of the multicohort single-arm phase II CheckMate 205 trial. J Clin Oncol 2018;36:1428-39.

24. Garcia-Manero G, Sasaki K, Montalban-Bravo G, et al. A phase II study of nivolumab or ipilimumab with or without azacitidine for patients with myelodysplastic syndrome (MDS) [abstract]. Blood 2018;132(suppl 1):465.

25. Ansell SM, Minnema MC, Johnson P, et al. Nivolumab for relapsed/refractory diffuse large B-cell lymphoma in patients ineligible for or having failed autologous transplantation: a single-arm, phase II study. J Clin Oncol 2019;37:481-9.

26. Daver N, Garcia-Manero G, Basu S, et al. Efficacy, safety, and biomarkers of response to azacitidine and nivolumab in relapsed/refractory acute myeloid leukemia: a nonrandomized, open-label, phase 2 study. Cancer Discov 2019; 9:370-83.

27. Younes A, Brody J, Carpio C, et al. Safety and activity of ibrutinib in combination with nivolumab in patients with relapsed non-Hodgkin lymphoma or chronic lymphocytic leukaemia: a phase 1/2a study. Lancet Haematol 2019;6:e67-78.

28. Green MR, Monti S, Rodig SJ, et al. Integrative analysis reveals selective 9p24.1 amplification, increased PD-1 ligand expression, and further induction via JAK2 in nodular sclerosing Hodgkin lymphoma and primary mediastinal large B-cell lymphoma. Blood 2010;116:3268-77.

29. Ansell S, Armand P, Timmerman JM, et al. Nivolumab in patients (Pts) with relapsed or refractory classical Hodgkin lymphoma (R/R CHL): clinical outcomes from extended follow-up of a phase 1 study (CA209-039) [abstract]. Blood 2015;126:583.

30. Ding W, LaPlant BR, Call TG, et al. Pembrolizumab in patients with CLL and Richter transformation or with relapsed CLL. Blood 2017;129:3419-27.

31. Yang H, Bueso-Ramos C, DiNardo C, et al. Expression of PDL1, PD-L2, PD-1 and CTLA4 in myelodysplastic syndromes is enhanced by treatment with hypomethylating agents. Leukemia 2014;28:1280-8.

32. Garcia-Manero G, Daver NG, Montalban-Bravo G, et al. A phase II study evaluating the combination of nivolumab (Nivo) or ipilimumab (Ipi) with azacitidine in pts with previously treated or untreated myelodysplastic syndromes (MDS) [abstract]. Blood 2016;128:344.

33. Armand P, Shipp MA, Ribrag V, et al. Programmed death-1 blockade with pembrolizumab in patients with classical Hodgkin lymphoma after brentuximab vedotin failure.JClin Oncol 2016;34:3733-9.

34. Garcia-Manero G, Tallman MS, Martinelli G, et al. Pembrolizumab, a PD-1 inhibitor, in patients with myelodysplastic syndrome (MDS) after failure of hypomethylating agent treatment [abstract]. Blood 2016;128:345.

35. Armand P, Rodig S, Melnichenko V, et al. Pembrolizumab in relapsed or refractory primary mediastinal large B-cell lymphoma. J Clin Oncol 2019;37:3291-9.

36. Chen R,ZinzaniPL, LeeHJ, etal. Pembrolizumab in relapsed or refractory Hodgkin lymphoma: 2-year follow-up of KEYNOTE087. Blood 2019;134:1144-53.

37. Zinzani PL, Ribrag V, Moskowitz CH, et al. Safety and tolerability of pembrolizumab in patients with relapsed/ refractory primary mediastinal large B-cell lymphoma.Blood 2017;130:267-70.

38. Chen R, Zinzani PL, Fanale MA, etal. on behalf of KEYNOTE-087. Phase II study of the efficacy and safety of pembrolizumab for relapsed/refractory classic Hodgkin lymphoma.JClin Oncol 2017;35:2125-32.

39. Long GV, Tykodi SS, Schneider JG, et al. Assessment of nivolumab exposure and clinical safety of $480 \mathrm{mg}$ every
4 weeks flat-dosing schedule in patients with cancer. Ann Oncol 2018;29:2208-13.

40. Gormley NJ, Pazdur R. Immunotherapy combinations in multiple myeloma-known unknowns. $N$ Engl J Med 2018;379:1791-5.

41. Haverkos BM, Abbott D, Hamadani M, et al. PD-1 blockade for relapsed lymphoma post-allogeneic hematopoietic cell transplant: high response rate but frequent GVHD. Blood 2017;130:221-8.

42. Herbaux C, Gauthier J, Brice P, et al. Efficacy and tolerability of nivolumab after allogeneic transplantation for relapsed Hodgkin lymphoma. Blood 2017;129:2471-8.

43. IjazA, Khan AY, Malik SU, et al. Significant risk of graft-versushost disease with exposure to checkpoint inhibitors before and after allogeneic transplantation. Biol Blood Marrow Transplant 2019;25:94-9.

44. Ansell SM, Hurvitz SA, Koenig PA, et al. Phase I study of ipilimumab, an anti-CTLA-4 monoclonal antibody, in patients with relapsed and refractory B-cell non-Hodgkin lymphoma. Clin Cancer Res 2009;15:6446-53.

45. Bashey A, Medina B, Corringham S, et al. CTLA4 blockade with ipilimumab to treat relapse of malignancy after allogeneic hematopoietic cell transplantation. Blood 2009;113:1581-8.

46. Davids MS, Kim HT, Bachireddy P, et al. on behalf of the Leukemia and Lymphoma Society Blood Cancer Research Partnership. Ipilimumab for patients with relapse after allogeneic transplantation. N Engl J Med 2016;375:143-53.

47. Khouri IF, Fernandez Curbelo I, Turturro F, et al. Ipilimumab plus lenalidomide after allogeneic and autologous stem cell transplantation for patients with lymphoid malignancies. Clin Cancer Res 2018;24:1011-18.

48. Daver N, Alfayez M, Garcia-Manero G, et al. Safety, efficacy, and biomarkers of response to azacitidine (AZA) with nivolumab (NIVO) and ipilimumab (IPI), and AZA with NIVO in R/R acute myeloid leukemia: a non-randomized, phase 2 study [abstract S1615]. Presented at: The 24th European Hematology Association Congress; 16 June 2019; Amsterdam, Netherlands. [Available online at: https://library.ehaweb .org/eha/2019/24th/267369/naval.daver.safety.efficacy.and .biomarkers.of.response.to.azacitidine.28aza29.html?f= listing\%3D3\%2Abrowseby\%3D8\%2Asortby\%3D2\%2Amedia \%3D3\%2Atopic\%3D1574; cited 10 March 2020]

49. Topp MS, Gökbuget N, Zugmaier G, et al. Phase II trial of the anti-CD19 bispecific T cell-engager blinatumomab shows hematologic and molecular remissions in patients with relapsed or refractory B-precursor acute lymphoblastic leukemia. J Clin Oncol 2014;32:4134-40.

50. Kantarjian H, Stein A, Gökbuget N, et al. Blinatumomab versus chemotherapy for advanced acute lymphoblastic leukemia. N Engl J Med 2017;376:836-47.

51. Martinelli G, Boissel N, Chevallier P, et al. Complete hematologic and molecular response in adult patients with relapsed/ refractory Philadelphia chromosome-positive B-precursor acute lymphoblastic leukemia following treatment with blinatumomab: results from a phase II, single-arm, multicenter study. J Clin Oncol 2017;35:1795-802.

52. Gökbuget N, Dombret H, Bonifacio M, et al. Blinatumomab for minimal residual disease in adults with B-cell precursor acute lymphoblastic leukemia. Blood 2018;131:1522-31.

53. Viardot A, Goebeler ME, Hess G, et al. Phase 2 study of the bispecific T-cell engager (BiTE) antibody blinatumomab in relapsed/refractory diffuse large B-cell lymphoma. Blood 2016;127:1410-16.

54. Goebeler ME, Knop S, Viardot A, et al. Bispecific T-cell engager (BiTE) antibody construct blinatumomab for the treatment of patients with relapsed/refractory non-Hodgkin lymphoma: final results from a phase I study. JClin Oncol 2016;34:1104-11. 